\title{
The upside of stress: a mechanism for the positive motivational role of corticotropin releasing factor
}

\author{
Julia C. Lemos ${ }^{1}$ and Veronica A. Alvarez ${ }^{2,3,4}$ \\ Neuropsychopharmacology (2020) 45:219-220; https://doi.org/10.1038/s41386-019-0510-9
}

Intuitively, we know that salient environmental stimuli, even when stressful, can trigger an internal state of urgency that focuses our attention, motivates us to work harder, encourages us to explore new spaces or people, and helps us achieve specific goals. Despite its known benefits, the neural mechanisms that underlie these positive motivational qualities of acute stress remain poorly understood. In the past 10 years, evidence has emerged pointing to a new role for the neuropeptide corticotropin-releasing factor (CRF). CRF is a well-studied stress-associated neuropeptide. A rich literature exists demonstrating neuronal substrates of CRF-evoked energy mobilization, fear, and anxiety. However, when acting in the nucleus accumbens (NAc), CRF has been shown to promote exploratory behaviors and invigoration for reward [1, 2]. Yet, the cellular mechanism(s) mediating these positive motivational actions of CRF in the NAc were not known.

In a study published two months ago, we showed that CRF type 1 receptors (CRF-R1) are ubiquitously expressed on cholinergic interneurons within the NAc of adult male mice [3]. We found that CRF produces a robust increase in action potential firing in cholinergic interneurons via CRF-R1 activation and CAMP dependent mechanisms [3]. Cholinergic interneurons form dense axonal ramifications, and therefore, through acetylcholine modulation, can act as master regulators of accumbal output. Previous work had shown that selective ablation of cholinergic interneurons disrupts locomotion and enhanced dopamine transmission triggered by an acute stressor, indicating this cell population plays a critical role in adaptive stress processing [4]. Moreover, work from the Greengard laboratory and others has shown that suppression of cholinergic interneuron firing through a variety of cell-type specific transgenic or chemogenetic manipulations produces behaviors consistent with a depression-like state in mice [5] that is accompanied by a reduction in reward-evoked dopamine release [6]. Thus, we reasoned that the CRF mediated increase of cholinergic interneuron firing may facilitate pathways that drive the opposite behaviors: active coping and hedonic behaviors such as reward consumption. This notion is supported by our original findings that CRF both potentiates dopamine and facilitates appetitive behaviors when acting in the NAc. In this more recent report, we further show that this effect is, in part, due to activation of muscarinic type 5 receptors (M5) on dopamine neuron projections [3]. We propose that CRF's potentiation of cholinergic and dopaminergic transmission in the NAc is an underlying mechanism for the positive motivational qualities of acute stressors.

We further speculate that vulnerabilities to neuropsychiatric diseases such as anxiety, depression, and addiction may develop due to a diminution of the positive qualities of stress, not only an exacerbation of the negative qualities of stress. Studies in human subjects demonstrate disfunction in NAc activity in patients with depression compared to healthy controls in response to positive and negative stimuli using fMRI [7, 8]. Moreover, in mice, GasDREADD activation in accumbal cholinergic interneurons was able to rescue depression-like phenotypes induced by chronic stress [5]. Thus, we remain hopeful that as we expand our understanding of the neuronal substrates that underlie the positive motivational qualities of stress and stress-associated neuropeptides like CRF, we may get closer to understanding the etiology of these diseases and improve treatment.

\section{FUNDING AND DISCLOSURE}

This study was funded by the Intramural Programs of NIAAA, NINDS (ZIA-AA000421) to VAA, K99/R00 Pathway to Independence award (MH109627) to JCL and 2017 Innovation Award from NIH-DDIR to VAA. The authors declare that they have no conflict of interest.

\section{ACKNOWLEDGEMENTS}

We thank Dr. Jurgen Wess for the M5KO mice. We are grateful to Dr. Steven Vogel for access to the confocal microscope. We thank Dr. David Lovinger and other members of the Alvarez lab for helpful comments and discussion.

\section{ADDITIONAL INFORMATION}

Publisher's note Springer Nature remains neutral with regard to jurisdictional claims in published maps and institutional affiliations.

\section{REFERENCES}

1. Lemos JC, Wanat MJ, Smith JS, Reyes BA, Hollon NG, Van Bockstaele, et al. Severe stress switches CRF action in the nucleus accumbens from appetitive to aversive. Nature. 2012;490:402-6. https://doi.org/10.1038/nature11436.

2. Pecina S, Schulkin J, Berridge KC. Nucleus accumbens corticotropin-releasing factor increases cue-triggered motivation for sucrose reward: paradoxical positive incentive effects in stress? BMC Biol. 2006;4:8.

3. Lemos JC, Shin JH, Alvarez VA. Striatal cholinergic interneurons are a novel target of corticotropin releasing factor. J Neurosci. 2019;39:5647-61. https://doi.org/ 10.1523/JNEUROSCI.0479-19.2019.

4. Laplante F, Dufresne MM, Ouboudinar J, Ochoa-Sanchez R, Sullivan RM. Reduction in cholinergic interneuron density in the nucleus accumbens attenuates local extracellular dopamine release in response to stress or amphetamine. Synapse. 2013;67:21-29. https://doi.org/10.1002/syn.21612.

5. Cheng J, Umschweif G, Leung J, Sagi Y, Greengard P. HCN2 channels in cholinergic interneurons of nucleus accumbens shell regulate depressive behaviors. Neuron. 2019;101:662-72 e665. https://doi.org/10.1016/j.neuron.2018.12.018.

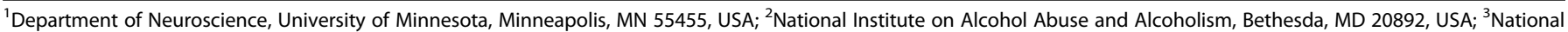
Institute on Drug Abuse, Bethesda, MD 20892, USA and ${ }^{4}$ Center on Compulsive Behaviors, Intramural Research Program, NIH, Bethesda, MD 20892, USA

Correspondence: Julia C. Lemos (jlemos@umn.edu)
}

Published online: 11 September 2019 
6. Hanada $Y$, Kawahara $Y$, Ohnishi YN, Shuto T, Kuroiwa M, Sotogaku N, et al. p11 in cholinergic interneurons of the nucleus accumbens is essential for dopamine responses to rewarding stimuli. eNeuro. 2018;5, https://doi.org/10.1523/ ENEURO.0332-18.2018.

7. Admon R, Holsen LM, Aizley $H$, Remington A, Whitfield-Gabrieli S, Goldstein $J M$, et al. Striatal hypersensitivity during stress in remitted individuals with recurrent depression. Biol Psychiatry. 2015;78:67-76. https://doi.org/10.1016/j. biopsych.2014.09.019.

8. Pizzagalli DA, Holmes AJ, Dillon DG, Goetz EL, Birk JL, Bogdan R, et al. Reduced caudate and nucleus accumbens response to rewards in unmedicated individuals with major depressive disorder. Am J Psychiatry. 2009;166:702-10. https://doi.org/ 10.1176/appi.ajp.2008.08081201.
Open Access This article is licensed under a Creative Commons Attribution 4.0 International License, which permits use, sharing, adaptation, distribution and reproduction in any medium or format, as long as you give appropriate credit to the original author(s) and the source, provide a link to the Creative Commons license, and indicate if changes were made. The images or other third party material in this article are included in the article's Creative Commons license, unless indicated otherwise in a credit line to the material. If material is not included in the article's Creative Commons license and your intended use is not permitted by statutory regulation or exceeds the permitted use, you will need to obtain permission directly from the copyright holder. To view a copy of this license, visit http://creativecommons.org/licenses/by/4.0/.

\title{
Dopamine release drives motivation, independently from dopamine cell firing
}

\author{
Ali Mohebi (iD) and Joshua D. Berke ${ }^{1}$ \\ Neuropsychopharmacology (2020) 45:220; https://doi.org/10.1038/s41386-019-0492-7
}

Despite decades of study, fundamental aspects of dopamine biology are still being revealed.

Dopamine release in the forebrain has at least two distinct functions: it invigorates current behavior (motivation) [1] and influences future behavior (learning) [2]. The learning role seems, at least in part, to involve brief bursts of dopamine cell firing signaling reward prediction errors [3]. This "phasic" dopamine signal helps adjust future reward expectations, through the modification of synaptic strengths in forebrain targets [4]. This is a compelling account of reinforcement learning mechanisms, but does not describe how dopamine achieves more immediate motivational functions.

It has been argued that motivation is mediated by distinct, slower changes in "tonic" dopamine cell firing. This now appears not to be the case [5]. In rats working for sugar rewards, we directly compared the firing of optogenetically identified midbrain dopamine cells (in the ventral tegmental area) with forebrain dopamine release (measured using microdialysis, voltammetry, and optical sensors). We found that dopamine release increases with reward expectation-and thereby enhances the animals' willingness to expend effort $[1,5]$. Crucially, however, we found no corresponding change in dopamine cell firing.

Instead, this motivational aspect of dopamine release seems to be locally controlled within forebrain subregions. In both striatum and cortex we found specific "hotspots" (nucleus accumbens core and ventral prelimbic cortex) where dopamine release covaried with reward expectation [5]. These spatial foci stand in contrast to the canonical concept of dopaminergic reward prediction errors being "broadcast" throughout the forebrain.

There are many mechanisms that can achieve local control of dopamine release [6], most obviously the nicotinic acetylcholine receptors on dopamine terminals. The axons of striatal cholinergic interneurons form a very dense network of release sites closely intermingled with dopamine varicosities. Artificial stimulation of striatal cholinergic neurons very rapidly evokes dopamine release.

Although the local control of dopamine release has long been studied, its functional and computational significance is only now coming into focus. A better understanding of how dopamine release is regulated in behaving animals may provide a critical foundation for our understanding of neurological and psychiatric disorders, and the development of novel pharmacological therapies.

\section{FUNDING AND DISCLOSURE}

Our work on dopamine has been supported by the National Institute on Drug Abuse, the National Institute of Mental Health, the National Institute on Neurological Disorders and Stroke, the University of Michigan, Ann Arbor, and the University of California, San Francisco. The authors declare no competing interests.

\section{ADDITIONAL INFORMATION}

Publisher's note: Springer Nature remains neutral with regard to jurisdictional claims in published maps and institutional affiliations.

\section{REFERENCES}

1. Hamid AA. et al. Mesolimbic dopamine signals the value of work. Nat. Neurosci. 2015:1-13. https://doi.org/10.1038/nn.4173

2. Berke JD. What does dopamine mean? Nat. Neurosci. 2018;1. https://doi.org/ 10.1038/s41593-018-0152-y

3. Schultz W, Dayan P, Montague PR. A neural substrate of prediction and reward. Science. 1997:275:1593-1599.

4. Yagishita S. et al. A critical time window for dopamine actions on the structural plasticity of dendritic spines. Science. 2014;345:1616-1620.

5. Mohebi A. et al. Dissociable dopamine dynamics for learning and motivation. Nature. 2019. https://doi.org/10.1038/s41586-019-1235-y

6. Rice ME, Patel JC, Cragg SJ. Dopamine release in the basal ganglia. Neuroscience. 2011;198:112-137. 